\title{
GAIA Level 2 Postpartum Hemorrhage
}

National Cancer Institute

\section{Source}

National Cancer Institute. GAIA Level 2 Postpartum Hemorrhage. NCI Thesaurus. Code C128001.

GAIA Level 2 Postpartum Hemorrhage is defined by the presence of the following criteria: genital bleeding after delivery with at least one of the following: a) Measured abnormal bleeding (1000 ml or more); or b) Any bleeding leading to hypotension or blood transfusion. 